\title{
CURRENT CONTROLLED VSC FOR REACTANCE MODULATION AND VOLTAGE DROP COMPENSATION ON POWER TRANSMISSION LINES
}

\author{
M. A. Noman ${ }^{1}$, S. A. Al-Ghamdi ${ }^{2, *}$ \\ Electrical Engineering Department, Al Baha University, Saudi Arabia
}

Received 22 November 2012, accepted 19 March 2013

\begin{abstract}
Reactance modulation of power transmission lines has great effects on load voltage control and on the stability of power transmission. Steady state voltage control can be easily achieved with conventional control devices such as switchable capacitors and reactors, while transient voltage control requires faster and more effective means of control [1]. In this paper, the transient voltage control is achieved by modulation of the net reactance of the transmission line using Voltage Drop Compensator (VDC) through hysteresis switching of a dc current from Voltage Source Converter (VSC) to charge/discharge a capacitor in series with the line. Modulation of the capacitor voltage by dc current from VSC improves the voltage control of the load, reduces the voltage drop on the transmission line, and improves the stability of the power transfer [2-4]. High frequency switching of the capacitor through charging/discharging process ensures faster response to transients in the input voltage and prevents it from appearing in the load. Fast response to variation in the input supply is done by comparing the load voltage to a sinusoidal reference voltage every time this voltage deviates from a fixed hysteresis window. Under this method of capacitor voltage control, no control is exerted on the dc current from VSC which can reach hundred amperes. In this paper a dc current controller is introduced to limit the dc current from VSC to a any value desired or to any other value necessary to keep the load voltage sinusoidal.
\end{abstract}

Index Terms - Flexible AC Transmission Systems (FACTS), Power System Stability, Voltage Drop Compensation.

\section{Introduction}

This paper presents three phase voltage drop compensator using Voltage Source Converter (VSC) to compensate for voltage drops on power transmission line reactance and to control the voltage at the load or at the bulk supply point of the load centres. The circuit of the Voltage Drop Compensator (VDC) is shown in Figure 1. A hysteresis controller is used to switch the VSC either to increase or to decrease the capacitor voltage whenever this voltage deviates from the reference voltage by the hysteresis window $\pm V_{H} / 2$, as illustrated in Figures 2 and 3. Controlling the load voltage in this way causes the capacitor voltage to be out of phase with the voltage drop across the transmission line reactance which compensates for the voltage drop across the transmission line reactance. The mathematical model of the three phase voltage drop compensator is presented in the

\footnotetext{
* Corresponding author.

E-mail address: mohnoman@ hotmail.com
} 
1111

M. A. Noman, S. A. Al-Ghamdi, Current controlled vsc for reactance modulation and voltage drop compensation on power transmission lines, pp. 1110 - 1126

equations (1-12) based on the switching table of VSC shown in the Appendix A.

$\frac{d i_{A}}{d t}=\frac{v_{S A}-R_{A} i_{A}-v_{C A}}{L_{A}}$

$\frac{d i_{B}}{d t}=\frac{v_{S B}-R_{B} i_{B}-v_{C B}}{L_{B}}$

$\frac{d i_{C}}{d t}=\frac{v_{S C}-R_{C} i_{C}-v_{C C}}{L_{C}}$

$\frac{d i_{a}}{d t}=\frac{2 v_{d c}-D_{a}\left(2 v_{C A}-v_{C B}-v_{C C}\right) / n_{1}-3 R_{V S C} i_{a}}{3 L_{F}}$

$\frac{d_{b}}{d t}=\frac{2 v_{d c}-D_{b}\left(2 v_{C B}-v_{C A}-v_{C C}\right) / n_{1}-3 R_{V S C} i_{b}}{3 L_{F}}$

$\frac{d i_{c}}{d t}=\frac{2 v_{d c}-D_{c}\left(2 v_{C C}-v_{C A}-v_{C B}\right) / n_{1}-3 R_{V S C} i_{c}}{3 L_{F}}$

$\frac{d v_{C A}}{d t}=\frac{i_{A}+D_{a} i_{a} / n_{1}}{C_{a c}}$

$\frac{d v_{C B}}{d t}=\frac{i_{B}+D_{b} i_{b} / n_{1}}{C_{a c}}$

$\frac{d v_{C C}}{d t}=\frac{i_{C}+D_{c} i_{c} / n_{1}}{C_{a c}}$

$v_{i a}=v_{o a}-v_{o a}^{*}$

$v_{i b}=v_{o b}-v_{o b}^{*}$

$v_{i c}=v_{o c}-v_{o c}^{*}$

The resistances and the inductances $R_{A}$ and $L_{A}$ included in the above equations are the resistances and the inductances of the source, the transmission line and the load in phase (A) derived from the VDC state equations. $\mathrm{As}_{R_{A}}$ and $L_{A}$ are defined for phase (A), the same values are defined for phases (B) and (C). The currents $i_{a}, i_{b}$, and $i_{c}$ are the output currents of the dc/ac inverter. In the above equations, $D_{a}=(2 d a-1.0), D_{b}=(2 d b-1.0)$, $D_{c}=(2 d c-1.0)$. In the case of increasing the capacitor voltage, the parameter

Journal of Engineering Sciences, Assiut University, Faculty of Engineering, Vol. 41, No. 3, May, 2013,E-mail address: jes@aun.edu.eg 
M. A. Noman, S. A. Al-Ghamdi, Current controlled vsc for reactance modulation and voltage drop compensation on power transmission lines, pp. 1110 - 1126

$d a=1.0, d b=1.0, d c=1.0$ and these parameters are equal to zero for decreasing the capacitor voltage. The voltages $v_{i a}, v_{i b}, v_{i c}$ in Eqns. (10-12) are the voltage errors between the actual load voltages $v_{o}$ and the reference voltages $v_{o}^{*}$ in the phases $\mathrm{a}, \mathrm{b}$, and $\mathrm{c}$. The voltages $v_{C A}, v_{C B}$, and $v_{C C}$ in Eqns. (7-9) are the voltages across the ac capacitors in phases $\mathrm{A}, \mathrm{B}$, and $\mathrm{C}$, respectively.

\section{Circuit operating principles}

The block diagram of the Voltage Drop Compensator (VDC) is shown in Fig. 4 for phase (a) of the transmission line. This block diagram is based on the mathematical model in Eqns. (1-12) and on the derivations shown in Appendix A. The capacitor voltage is modulated by the dc current from the VSC, as seen from (7A), to control the load voltage through hysteresis switching of VSC whenever the capacitor voltage deviates from the reference voltage by the hysteresis window. The error signal resulted from the hysteresis controller in Figure 2 is $v_{i}=v_{c}^{*}-v_{c}$, where the reference capacitor voltage is $v_{c}^{*}=v_{s}-v_{T L}-v_{o}^{*}$ and $v_{T L}$ is the voltage drop on and $v_{T L}$ is the voltage drop on the transmission line. However, from the circuit diagram of Figure 1, $v_{o}=v_{s}-v_{T L}-v_{c}$. Therefore, the error signal is actually equal to $v_{i}=v_{o}-v_{o}^{*}$ as depicted in Figure 3 . This means that the load voltage is actually controlled with respect to a sinusoidal reference voltage through the control of the capacitor voltage. The signs of the error signals of Eqns. (10-12) between the actual load voltages and the reference voltages in each phase, the hysteresis controller of Figure 3 will switch the power transistors either to increase or to decrease the ac capacitor voltages. Decreasing the ac capacitor voltages is done by inserting (-1) for $D_{a}, D_{b}$ and $D_{c}$ in Eqns. (4-9) whenever it is required to increase the output voltage.

Increasing the capacitor voltage is done by inserting $(+1)$ for $D_{a}, D_{b}$, and $D_{c}$ in the same equations whenever it required to decrease the output voltage. The hysteresis controller of the load voltage reverses the signs of the capacitor voltages $v_{C B C}, v_{C A C}$, and $v_{C A B}$ in Eqns. (4-6) all the time whenever the signs of Eqns. (10-12) is changed. This sign reversal is already accounted for in the signs of $D_{a}, D_{b}$ and $D_{c}$. The signs under $i_{a}, i_{b}$, and $i_{c}$ in Eqns. (7-9) are also reversed as a result of the hysteresis controller action. Therefore, the parameters $D_{a}, D_{b}, D_{c}$ in Eqns. (4-9) are used to express the nature of hysteresis switching resulted from Eqns. (10-12) and also to compress the size of the equations of the mathematical model. The dc voltage $v_{d c}$ in Eqns. (4-6) is generated by three phase rectifiers. Figure 4 shows the block diagram of Voltage Drop Compensator for phase $(\mathrm{A})$ of the transmission.

Journal of Engineering Sciences, Assiut University, Faculty of Engineering, Vol. 41, No. 3, May, 2013,E-mail address: jes@aun.edu.eg 
1113

M. A. Noman, S. A. Al-Ghamdi, Current controlled vsc for reactance modulation and voltage drop compensation on power transmission lines, pp. 1110 - 1126

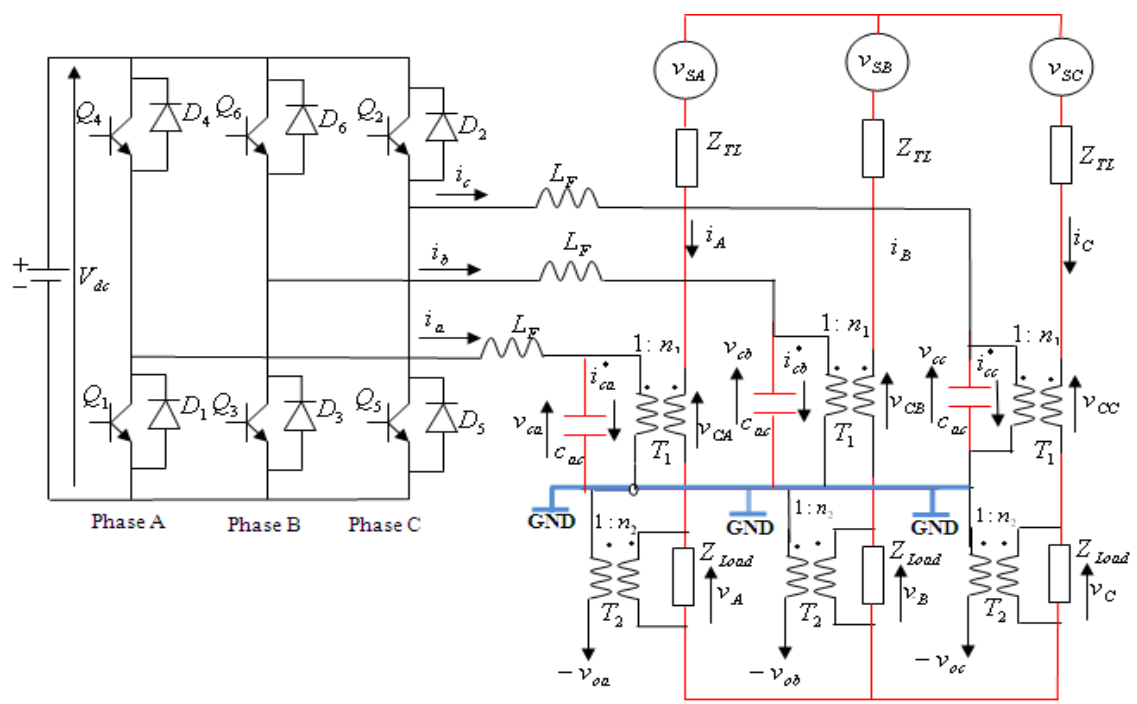

Fig. 1. Circuit Diagram of the Three Phase Voltage Drop Compensator on Power Transmission Lines

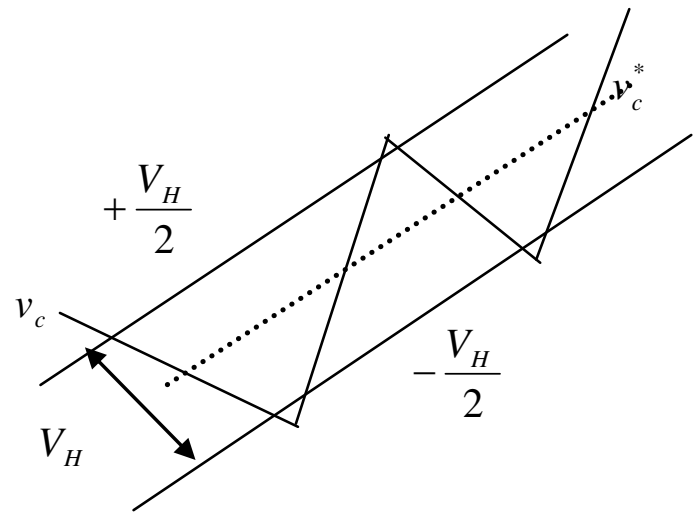

Fig. 2. Hysteresis Control of the capacitor voltage

$$
v_{i}=v_{c}^{*}-v_{c}
$$

Journal of Engineering Sciences, Assiut University, Faculty of Engineering, Vol. 41, No. 3, May, 2013, E-mail address: jes@aun.edu.eg 


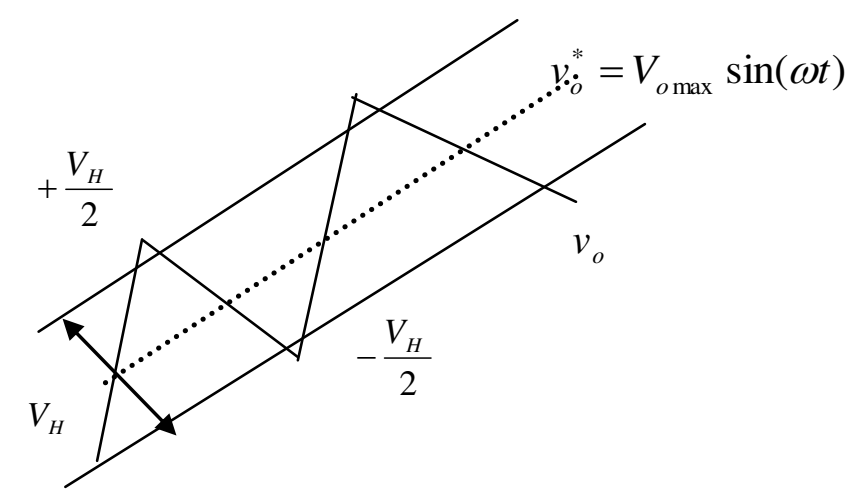

Fig. 3. Hysteresis Control of the load voltage

$$
v_{i}=v_{o}-v_{o}^{*}
$$

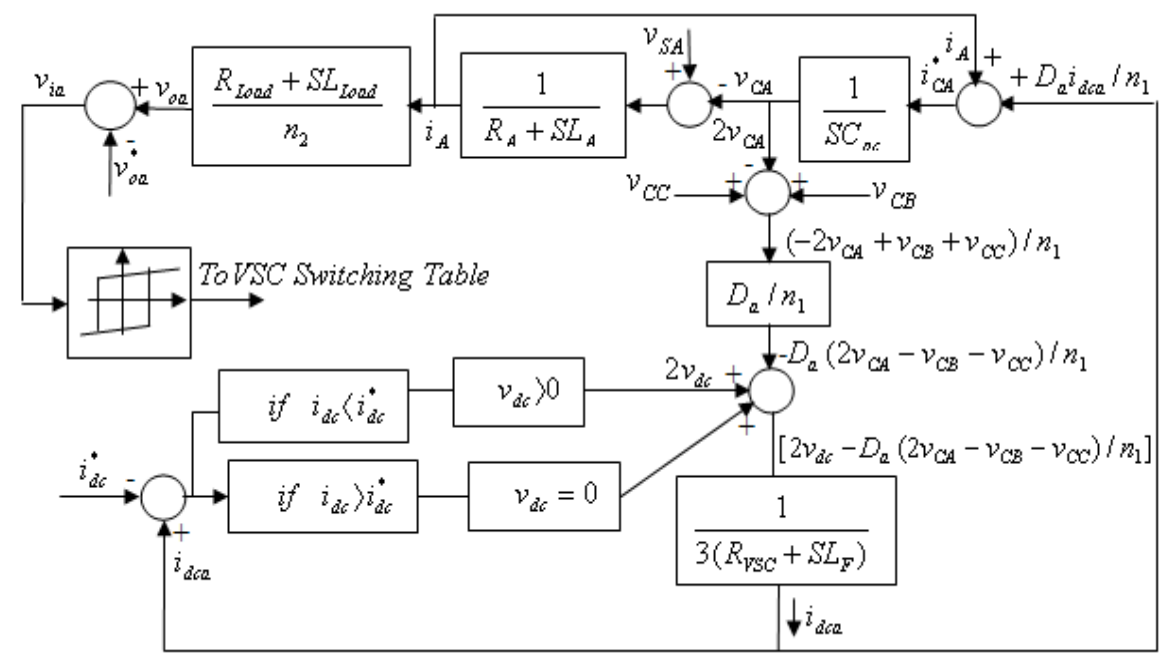

Fig. 4. Block Diagram of the Voltage Drop Compensator for phase (A) of the Transmission Line

Journal of Engineering Sciences, Assiut University, Faculty of Engineering, Vol. 41, No. 3, May, 2013,E-mail address: jes@aun.edu.eg 


\section{5}

M. A. Noman, S. A. Al-Ghamdi, Current controlled vsc for reactance modulation and voltage drop compensation on power transmission lines, pp. 1110 - 1126

\section{Performance of the voltage drop compensator on $380 \mathrm{kv}$ lines}

The performance of the voltage drop compensator is studied on a scaled laboratory model $360 \mathrm{~km}, 380 \mathrm{KV}$ transmission line with 360,720 , and $1080 \mathrm{VA}$ loads which represent 360, 720 and $1080 \mathrm{MVA}$ in the actual transmission line. The performance of the Voltage Drop Compensator is studied by computer simulation using a self-developed Fortran integration subroutine.

The parameters of the circuit are shown in Table 1 . Figures $(5,6,7)$ give the load and the source voltage waveforms without VDC in per units with loads 360, 720, and 1080 VA. These loads represent $1 \mathrm{pu}, 2 \mathrm{pu}$, and $3 \mathrm{pu}$, respectively. Figures $(8,9,10)$ show the load voltages with VDC under the same loads. From these Figures, it is clear the effects of the VDC on the voltage levels and on power angles between the sending and the receiving ends voltages of the power transmission line.

Table 1.

Parameters of the Transmission Line and Voltage Drop Compensator

\begin{tabular}{ccccc}
\hline \hline $\begin{array}{c}R_{T L}+R_{S} \\
(\Omega)\end{array}$ & $\begin{array}{c}L_{T L}+L_{S} \\
(m H)\end{array}$ & $C_{a c}$ & $C_{d c}$ & $L_{F}$ \\
& & $\mu F$ & $\mu F$ & $(m H)$ \\
& & & & \\
\hline 6.3 & 113 & 61 & 940 & 2 \\
\hline \hline
\end{tabular}

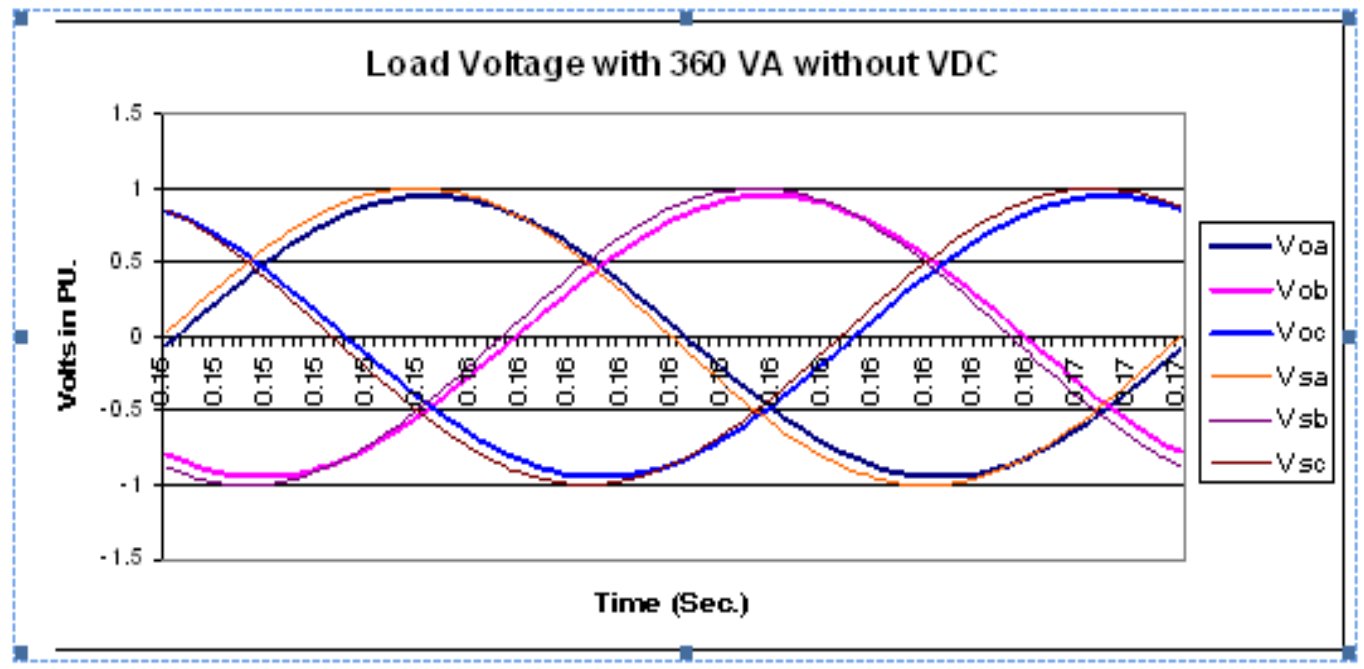

Fig. 5. Load voltages with 1pu Load (360 VA) without VDC $V_{o}=0.946$ in pu of $V_{s \max }$

Journal of Engineering Sciences, Assiut University, Faculty of Engineering, Vol. 41, No. 3, May, 2013,E-mail address: jes@aun.edu.eg 
M. A. Noman, S. A. Al-Ghamdi, Current controlled vsc for reactance modulation and voltage drop compensation on power transmission lines, pp. 1110 - 1126

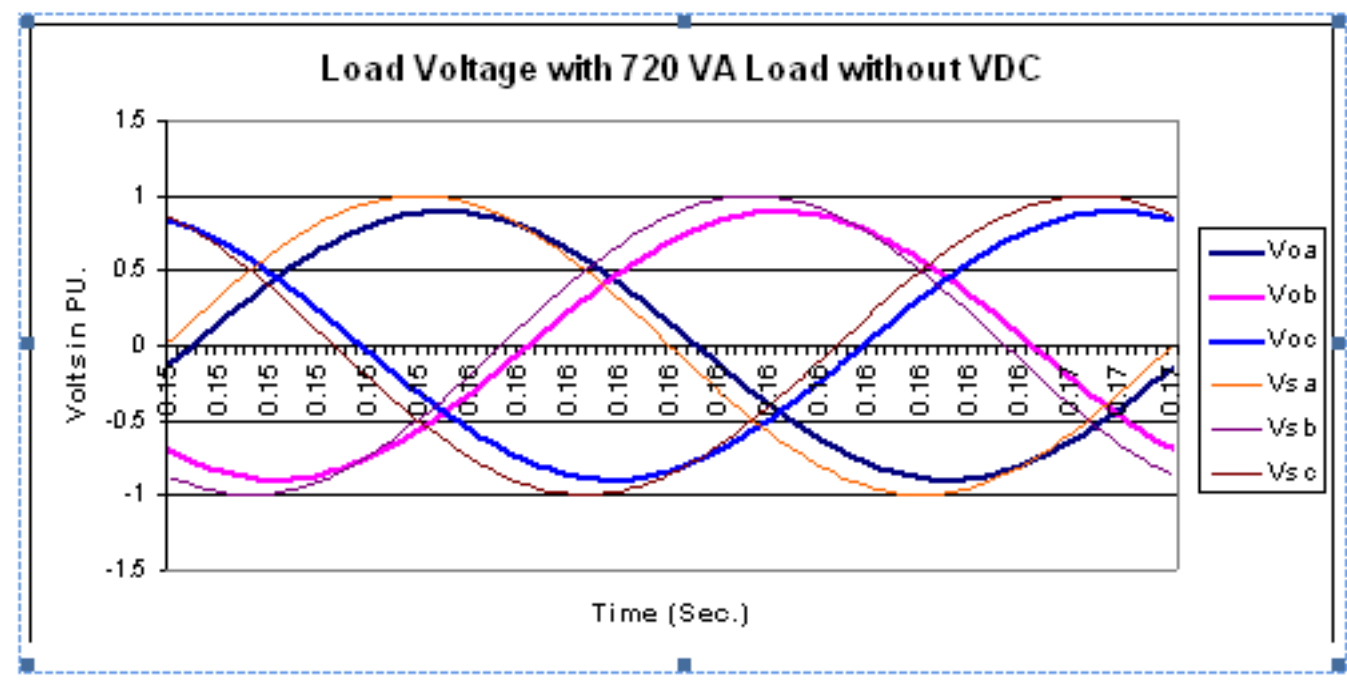

Fig. 6. Load Voltages with 2 pu Load (720 VA) without VDC, $V_{o}=0.886$ in pu of $V_{s \max }$

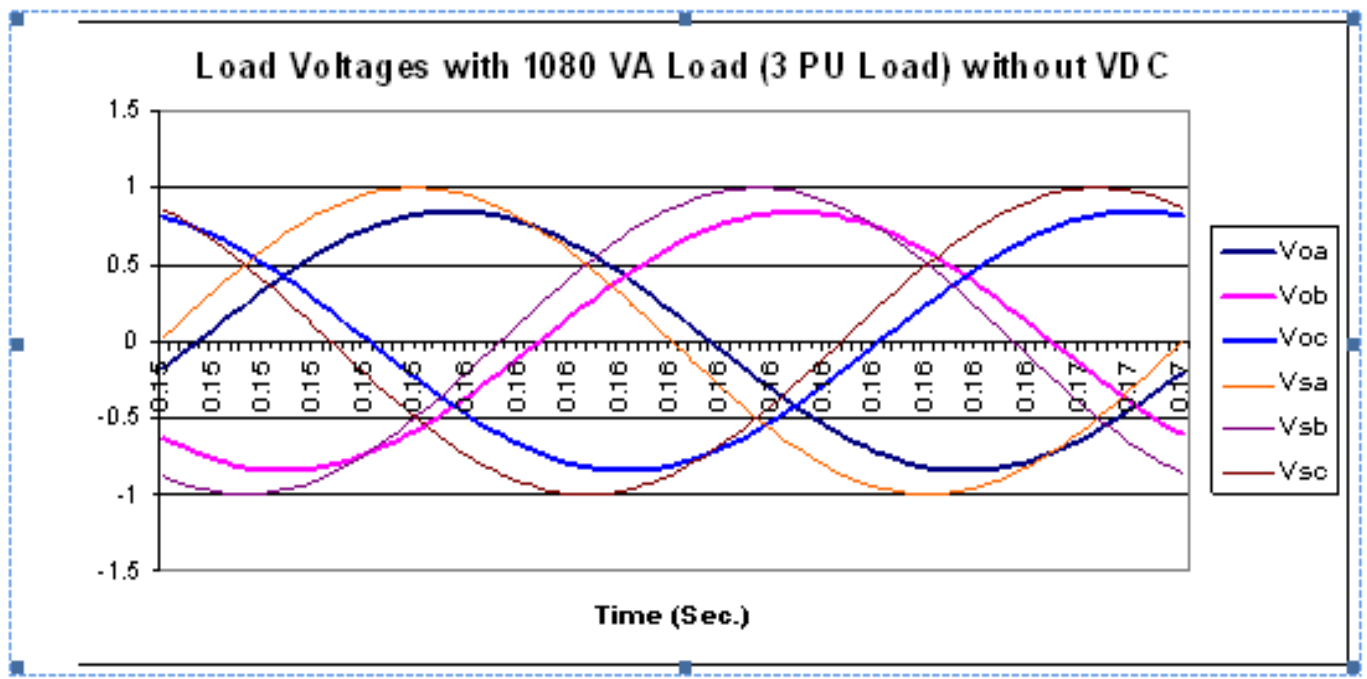

Fig. 7. Load Voltages with 3pu Load(1080 VA) without VDC, $V_{o}=0.845$ in pu of $V_{s \max }$

The waveforms of the actual and the reference voltages for phase (a) $v_{o a} \& v_{o a}^{*}$ coincide on each other in Fig. (8-10). The same thing the voltages of phases (b, c) coincide with their references, so that it is difficult to explicit them separately in the Figures. Table 3 shows the magnitudes of the voltages with VDC actions.

Journal of Engineering Sciences, Assiut University, Faculty of Engineering, Vol. 41, No. 3, May, 2013,E-mail address: jes@aun.edu.eg 


\section{7}

M. A. Noman, S. A. Al-Ghamdi, Current controlled vsc for reactance modulation and voltage drop compensation on power transmission lines, pp. 1110 - 1126

The dc link current associated with load voltage control in Fig. 8, 9 and 10 is shown in Fig. 11. It is required to limit this current to a value necessary to maintain the load voltage equal to the reference voltage. A dc link current controller is introduced which will limit this current to an acceptable value.

Table 2.

Switching Table of VSC of Fig. 1.

\begin{tabular}{|c|c|c|c|c|c|c|}
\hline Switching State & $\begin{array}{c}\mathrm{S} 1(1,0,0) \\
S_{a}\end{array}$ & $\begin{array}{c}\mathrm{S} 4(0,1,1) \\
S_{a}^{-}\end{array}$ & $\begin{array}{c}\mathrm{S} 3(0,1,0) \\
S_{b}\end{array}$ & $\begin{array}{c}\text { S6 }(1,0,1) \\
S_{b}^{-}\end{array}$ & $\begin{array}{c}\mathrm{S} 5(0,0,1) \\
S_{c}\end{array}$ & $\begin{array}{c}\mathrm{S} 2(1,1,0) \\
S_{c}^{-}\end{array}$ \\
\hline Opened VSC to regulate $v_{o}$ & Q4,Q3,Q5 & Q1,Q6,Q2 & Q1,Q6,Q5 & Q4,Q3,Q2 & Q1,Q3,Q2 & Q4,Q6,Q5 \\
\hline $\begin{array}{l}\text { Switched-off VSC to control } \\
\text { Inverter current }\end{array}$ & Q4 & Q1 & Q6 & Q3 & Q2 & Q5 \\
\hline $\begin{array}{l}\text { Opened VSC for inverter } \\
\text { current Freewheeling }\end{array}$ & D1,Q3,Q5 & D4,Q6,Q2 & Q1,D3,Q5 & Q4,D6,Q2 & Q1,Q3,D5 & Q4,Q6,D2 \\
\hline
\end{tabular}

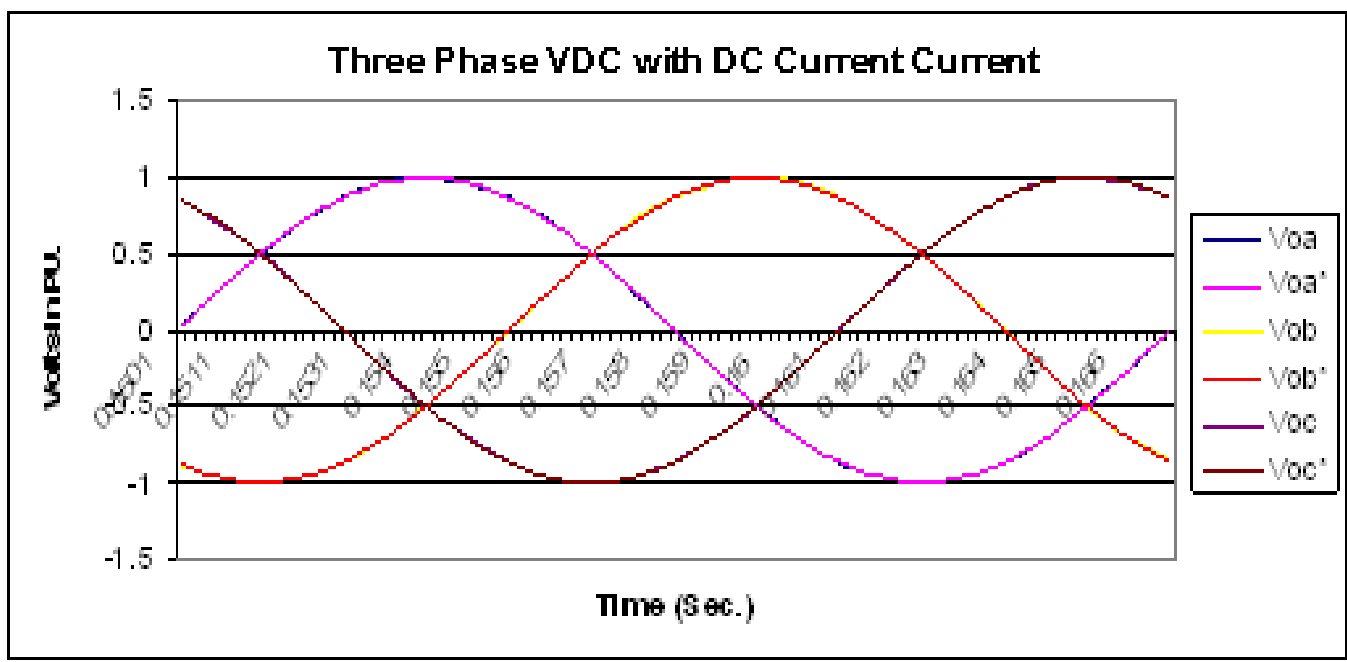

Fig. 8. Output Voltages under 1PU(360 VA) Load with VDC, $V_{o}=1.0$ in pu of $V_{s \max }$

Journal of Engineering Sciences, Assiut University, Faculty of Engineering, Vol. 41, No. 3, May, 2013,E-mail address: jes@aun.edu.eg 
M. A. Noman, S. A. Al-Ghamdi, Current controlled vsc for reactance modulation and voltage drop compensation on power transmission lines, pp. 1110 - 1126

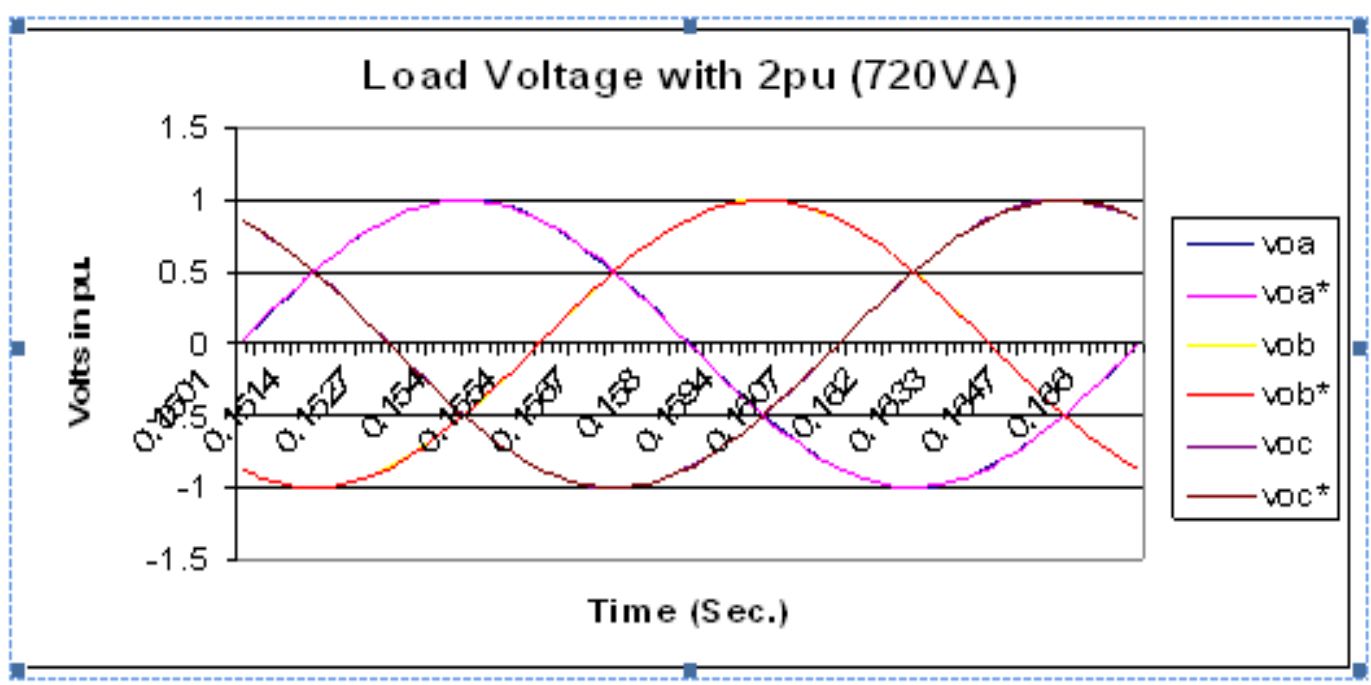

Fig. 9. Output Voltages under $2 \mathrm{PU}(720 \mathrm{VA}) \mathrm{Load}$ with VDC, $V_{o}=1.0$ in pu of $V_{s \max }$

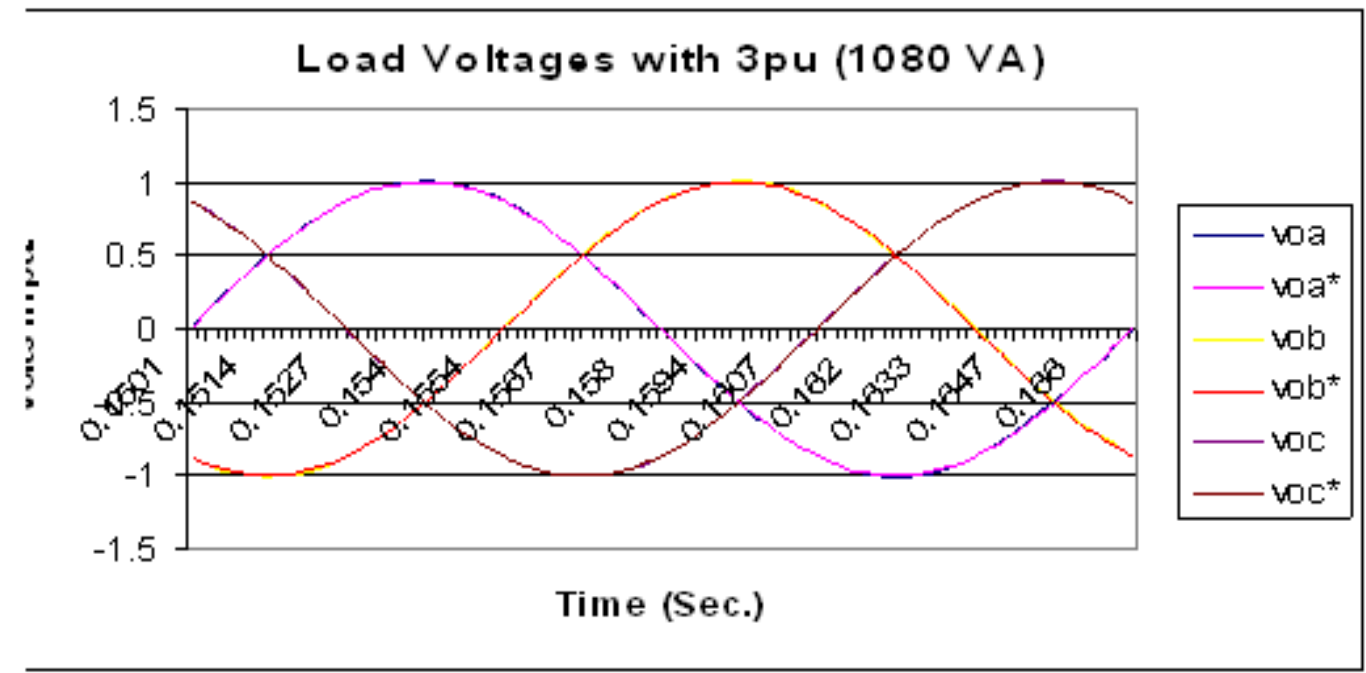

Fig. 10. Output Voltages under $3 \mathrm{PU}(1080 \mathrm{VA}) \mathrm{Load}$ with $\mathrm{VDC}, V_{o}=1.0$ in PU of $V_{s \max }$

Journal of Engineering Sciences, Assiut University, Faculty of Engineering, Vol. 41, No. 3, May, 2013,E-mail address: jes@aun.edu.eg 
M. A. Noman, S. A. Al-Ghamdi, Current controlled vsc for reactance modulation and voltage drop compensation on power transmission lines, pp. 1110 - 1126

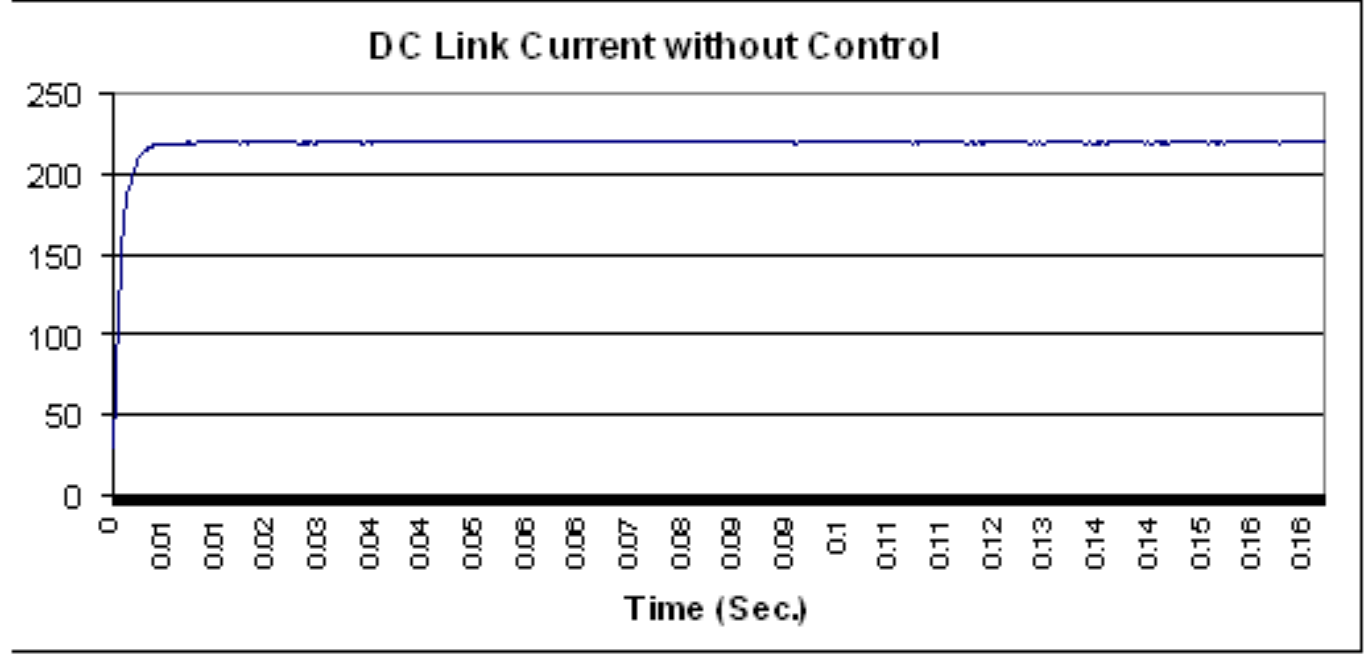

Figure 11. Inverter Current $=230 A$ under $3 P U$ (1080 VA) Load with VDC and without VSC Current Control.

\section{Control of the de link current}

Controlling the load voltage to follow a sinusoidal reference is associated with high dc current in VSC which can reach more than two hundred amperes as can be seen from Figure 11. To limit the dc current in VSC to some preset reference value, which will be necessary to maintain the load voltage equals to the reference voltage, the dc current in VSC is made to freewheel inside the ac capacitor and in the VSC switches whenever this current increases beyond the reference dc current. This freewheeling process is explained below for phase (a) according to Figure 1 as follows:

a) If $v_{o a}>v_{o a}^{*}+\frac{\Delta V_{H}}{2}$ the switching state is $\mathrm{S} 1(1,0,0)$. This state switches-on Q4, Q3, and Q5 to increase the capacitor voltage (actually the load voltage $v_{o a}$ is decreased) and whenever the current in VSC becomes greater than the inverter reference current $i^{*}$ by some preset value $i>i^{*}+\frac{\Delta I}{2}$, the switch $\mathrm{Q} 4$ is switched-off and the dc current will freewheel between the switches D1, Q3, Q5, and $C_{a c}$.

b) If $v_{o a}\left\langle v_{o a}^{*}-\frac{\Delta V_{H}}{2}\right.$ the switching state is $\mathrm{S} 4(0,1,1)$. This state switches-on $\mathrm{Q} 1, \mathrm{Q} 6$, Q2 to decrease the capacitor voltage (actually to increase the load voltage $v_{o a}$ ) and 2013,E-mail address: jes@aun.edu.eg 
M. A. Noman, S. A. Al-Ghamdi, Current controlled vsc for reactance modulation and voltage drop compensation on power transmission lines, pp. 1110 - 1126

whenever $i\rangle i^{*}+\frac{\Delta I}{2}$ the switch Q1 is switched-off, and the dc current is made to freewheel between the switches D4, Q6, Q2 and $C_{a c}$. Table 2 shows the switching table for switching VSC in the three phase Voltage Drop Compensator to control the load voltage and to maintain the inverter current $i$ in the VSC at a constant reference value $i^{*}$. The effects of dc current controller described above is presented in Fig. 12 and 13. In Fig. 12, three currents are shown for three loads. The reference dc current in the VSC, for each load case, is automatically adjusted during operation so that the deviation of the load voltage from the reference voltage should not exceed some specified value, such as $10 V_{H}$, where $V_{H}$ is width of the hysteresis window. The reference dc current can also be set equal to a fixed value for each load case without adjustment, as shown in Fig. 13. However, automatic adjustments of the dc reference current during operation gives better load voltage regulation. The voltage on different load is shown in Table 3. Table 3 shows the load voltage and the power angles between the sending and the receiving ends voltages due to the effects of VDC with DC current control from the VSC.

\section{Increased power transfer}

The voltage drops on the ac capacitor and on the transmission line are shown in Fig. 14 . These voltages are opposing each other. These voltages are out-of phase and increase linearly with the load current. Due to this compensation, more power can be transmitted over the line regardless of the load as long as it is less than the thermal limits of the line. The voltage on the load and the power angle values between the sending and the receiving ends voltages due to the effects of VDC with DC current control from the VSI.

\section{Conclusions}

Controlling the voltage across the load so that it can follow a sinusoidal reference voltage template using hysteresis controller can maintain a pure sinusoidal voltage across the load and also compensates for the voltage drop across transmission line reactance. Compensation for the transmission line reactance will increase the power transmission capacity of the line. The power transmitted can reach the thermal power limit of the line conductors. A three phase prototype of this design with controller is required to investigate the performance of the design in the three phase systems. The final goal of this research is to build a voltage drop compensator to operate on the existing power transmission lines to increase the power transfer to the load centers and to improve the voltage levels in the network and to solve the problems related to the right of way limitations and to improve the stability of power transfer.

Journal of Engineering Sciences, Assiut University, Faculty of Engineering, Vol. 41, No. 3, May, 2013, E-mail address: jes@aun.edu.eg 
1121

M. A. Noman, S. A. Al-Ghamdi, Current controlled vsc for reactance modulation and voltage drop compensation on power transmission lines, pp. 1110 - 1126

\section{Table 3.}

Effects of VDC on load voltage and power angle $\delta_{S R}=\delta_{S}-\delta_{R}$

\begin{tabular}{lllll}
\hline \hline \multirow{2}{*}{$S_{\text {Load }}$} & \multicolumn{2}{c}{ Without VDC } & \multicolumn{2}{c}{ With VDC and dc current control } \\
\cline { 2 - 4 }$($ MVA) & $V_{o a}$ & $\delta_{S R}$ inDeg. & $V_{o a}$ & $\delta_{S R}$ in \\
& in pu & & In pu & Deg. \\
360 & 0.946 & 5.4 & 1.0 & 0.0 \\
720 & 0.901 & 10.69 & 1.0 & 0.0 \\
1080 & 0.845 & 14.25 & 1.0 & 0.0 \\
\hline \hline
\end{tabular}

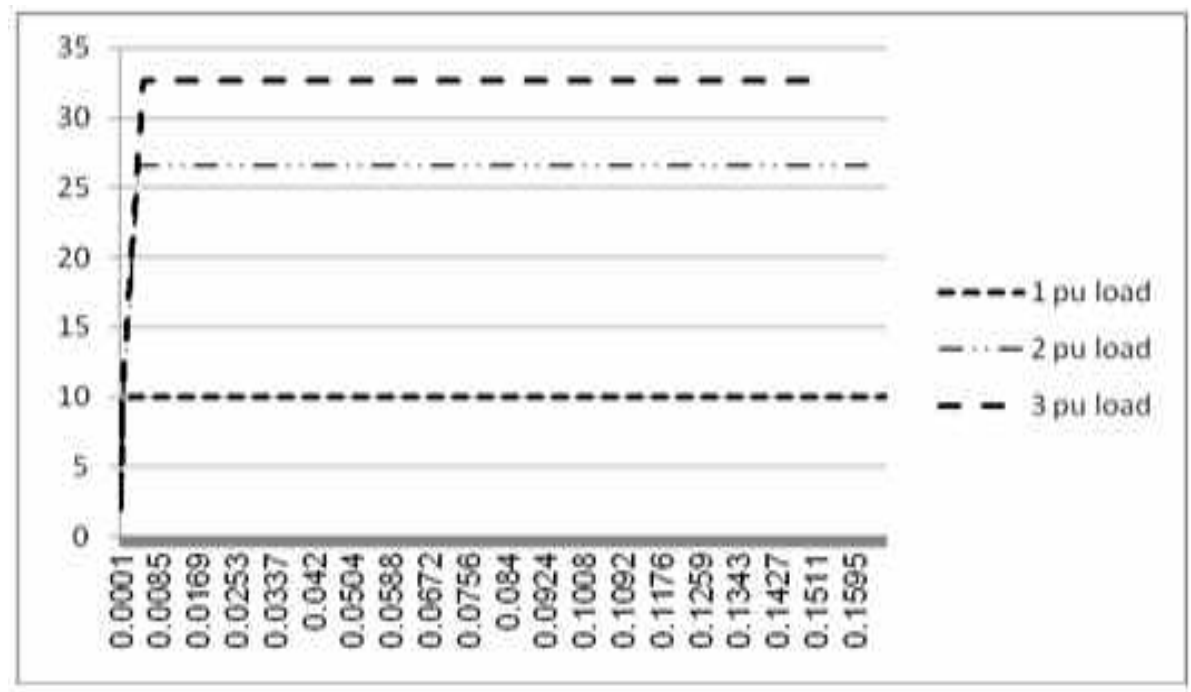

Fig. 12. DC Current from the VSC under Different Loads with Adjusted $i^{*}$ Reference Current.

Journal of Engineering Sciences, Assiut University, Faculty of Engineering, Vol. 41, No. 3, May, 2013,E-mail address: jes@aun.edu.eg 
M. A. Noman, S. A. Al-Ghamdi, Current controlled vsc for reactance modulation and voltage drop compensation on power transmission lines, pp. 1110 - 1126

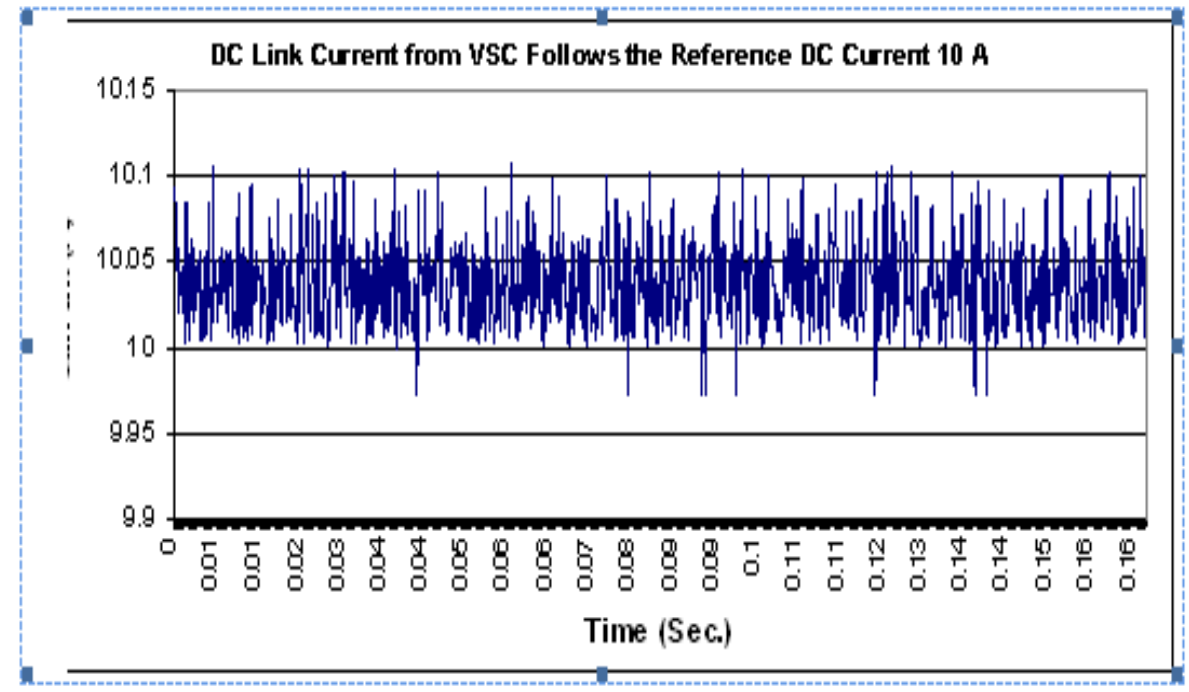

Fig. 13. Current from the VSC with fixed Reference DC Current setting $i^{*}=10 \mathrm{~A}$.

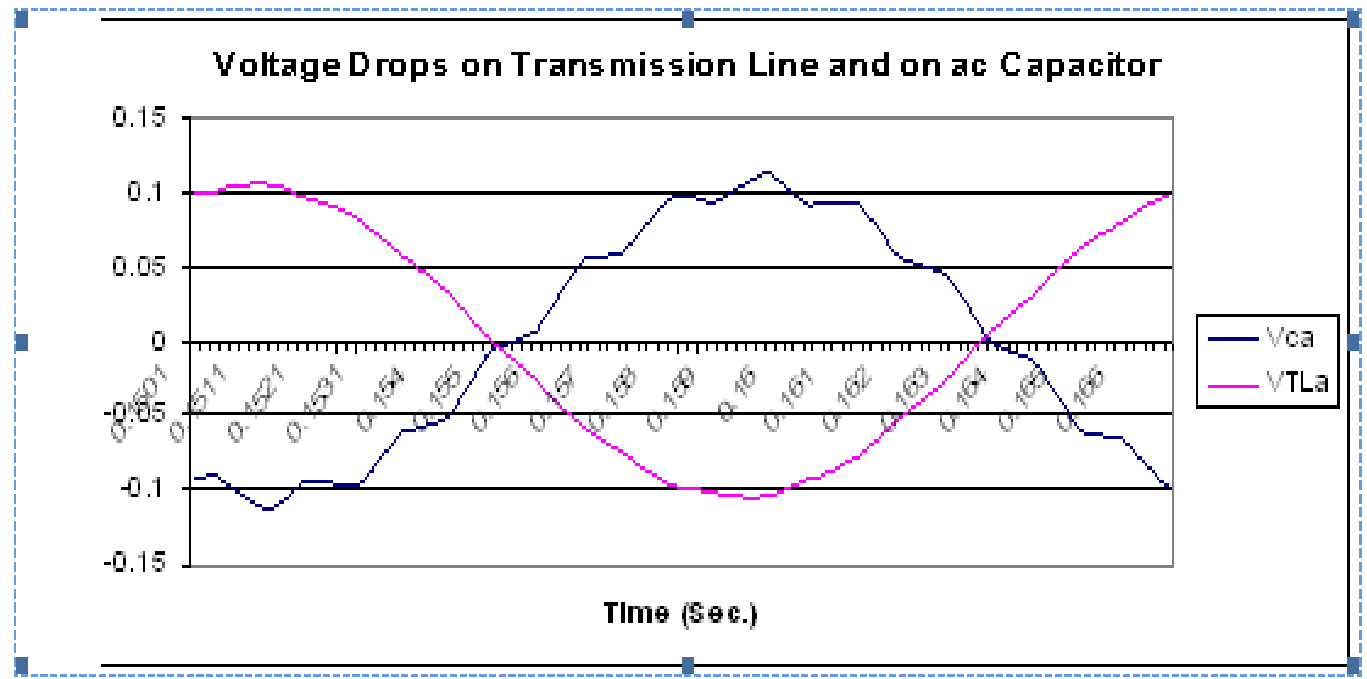

Fig. 14. Voltage Drops on the Transmission Line and on ac Capacitor for 360 VA load.

\section{References}

[1] A. J.P Ramos, H. Tyll, "Dynamic Performance of A Radial Weak Power Systems with Multiple Static VAR Compensator", IEEE transmission on Power Systems, Vol. 4, No. 4, Oct. 1989, pp. 1316-1325.

Journal of Engineering Sciences, Assiut University, Faculty of Engineering, Vol. 41, No. 3, May, 2013,E-mail address: jes@aun.edu.eg 
M. A. Noman, S. A. Al-Ghamdi, Current controlled vsc for reactance modulation and voltage drop compensation on power transmission lines, pp. 1110 - 1126

[2] Noman, Mohamed Ali, "A new Approach for Voltage Drop and Wave Shape Compensation", presented in AMSE-ISIS'97 Conference proceedings, pp. (43-49), which is held in Reggio Calabria, Italy, in the period Sept. 11-13, 1997.

[3] 3.Noman, Mohamed Ali , "Instantaneous Voltage controller as Voltage Drop Compensator for High Voltage Transmission Lines", "Middle East Power Systems Conference MEPCON96", PP. (74-79), Luxor, Egypt.

[4] Noman, Mohamed Ali and T. H. Ortmeyer, "Design and Operating Characteristics of a Series Voltage Controller", IEEE transmission on Power Delivery, Vol. 6, No. 4, Oct. 1991, pp. 1517-1523.

[5] Bon-Gwan Gu, Kwanghee Nam, “A DC-Link Capacitor Minimization Method Through Direct Capacitor Current Control", IEEE Transactions on Industry Applications, Vol. 42, NO:2. March/April 2006, 573-581.

[6] S. Tara Kalyani, G. Tulasiram Das, "Simulation of D-Q Control Systems for a Unified Power Flow Controller", ARPN Journal of Engineering and Applied Sciences, Vol. 2, No. 6, Dec. 2007: 10-19.

[7] Hideaki Fujita, Yasuhiro Watanabe, Hirofumi Akagi, "Transient Analysis of a Unified Power Flow Controller and its Application to Design of the DC-link Capacitor", 0-78035421-4/99 () 1999 IEEE, 626-631.

[8] S. Tara Kalyani, G. Tulasiram Das, "Simulation of Real and Reactive Power Flow Control with UPFC Connected to a Transmission Lines", Journal of Theoretical and Applied Information Technology, 2008 JATIT, 16-22.

\section{Appendix a}

Formulation of the mathematical model in the s-domain

$$
\begin{aligned}
& i_{A}=\frac{v_{S A}-v_{C A}}{R_{A}+S L_{A}} \\
& i_{B}=\frac{v_{S B}-v_{C B}}{R_{B}+S L_{B}} \\
& i_{C}=\frac{v_{S C}-v_{C C}}{R_{C}+S L_{C}} \\
& i_{a}=\frac{2 v_{d c}-D_{a}\left(2 v_{C A}-v_{C B}-v_{C C}\right) / n_{1}}{3\left(R_{V S C}+S L_{F}\right)} \\
& i_{b}=\frac{2 v_{d c}-D_{b}\left(2 v_{C B}-v_{C A}-v_{C C}\right) / n_{1}}{3\left(R_{V S C}+S L_{F}\right)} \\
& i_{c}=\frac{2 v_{d c}-D_{c}\left(2 v_{C C}-v_{C A}-v_{C B}\right) / n_{1}}{3\left(R_{V S C}+S L_{F}\right)}
\end{aligned}
$$

Journal of Engineering Sciences, Assiut University, Faculty of Engineering, Vol. 41, No. 3, May, 2013,E-mail address: jes@aun.edu.eg 
1124

M. A. Noman, S. A. Al-Ghamdi, Current controlled vsc for reactance modulation and voltage drop compensation on power transmission lines, pp. 1110 - 1126

$$
\begin{aligned}
& v_{C A}=\frac{i_{A}+D_{a} i_{a} / n_{1}}{S C_{a c}} \\
& v_{C B}=\frac{i_{B}+D_{b} i_{b} / n_{1}}{S C_{a c}} \\
& v_{C C}=\frac{i_{C}+D_{c} i_{c} / n_{1}}{S C_{a c}} \\
& v_{o a}=\left(\frac{R_{A}+S L_{A}}{n_{2}}\right) I_{A}
\end{aligned}
$$

In the above Eqns. $R_{V S C}, L_{F}$ are the resistance of the VSC and the inductance of the filter coils. $C_{a c}, C_{d c}$ are the capacitance of the dc and ac capacitors. $n_{1}, n_{2}$ are the ratios of transformers $T_{1}$ and $T_{2}$ in the circuit of Fig. 1 .

The switching table of the vsc

The VSC in the circuit of Fig. 1 are switched according to the Table A1, where V1, V2, V3, V4, V5, V6 are the switching states of the Voltage Source Converter. $S_{a}, S_{b}$, $S_{c}$ represent the VSC in phases (a), (b), (c) and $S_{a, b, c}=1$ means the upper VSC are on, while $S_{a, b, c}=0$ means the lower VSC are on. Based on these switching states, Equations (4-6) were derived.

\section{Dc current from vsc during freewheeling process}

Table A1 shows the switching states of VSC switches shown in Figure 1.Table A2 shows three main states and three reverse states to these main three states.

$$
\begin{aligned}
& v_{o b}=\left(\frac{R_{B}+S L_{B}}{n_{2}}\right) I_{B} \\
& v_{o c}=\left(\frac{R_{C}+S L_{C}}{n_{2}}\right) I_{C} \\
& i_{a}=\frac{-D_{a}\left(2 v_{C A}-v_{C B}-v_{C C}\right) / n_{1}}{3\left(R_{V S C}+S L_{F}\right)}
\end{aligned}
$$

Journal of Engineering Sciences, Assiut University, Faculty of Engineering, Vol. 41, No. 3, May, 2013,E-mail address: jes@aun.edu.eg 
1125

M. A. Noman, S. A. Al-Ghamdi, Current controlled vsc for reactance modulation and voltage drop compensation on power transmission lines, pp. 1110 - 1126

$$
\begin{aligned}
& i_{b}=\frac{-D_{b}\left(2 v_{C B}-v_{C A}-v_{C C}\right) / n_{1}}{3\left(R_{V S C}+S L_{F}\right)} \\
& i_{c}=\frac{-D_{c}\left(2 v_{C C}-v_{C A}-v_{C B}\right) / n_{1}}{3\left(R_{V S C}+S L_{F}\right)}
\end{aligned}
$$

Table A1.

Switching States of the VSC in Figure 1

\begin{tabular}{cccc}
\hline \hline State & $S_{a}$ & $S_{b}$ & $S_{c}$ \\
\hline V5 & 0 & 0 & 1 \\
V3 & 0 & 1 & 0 \\
V4 & 0 & 1 & 1 \\
V1 & 1 & 0 & 0 \\
V6 & 1 & 0 & 1 \\
V2 & 1 & 1 & 0 \\
\hline \hline
\end{tabular}

Table A2.

Main and Reverse States for switching of VSC switches in Figure 1

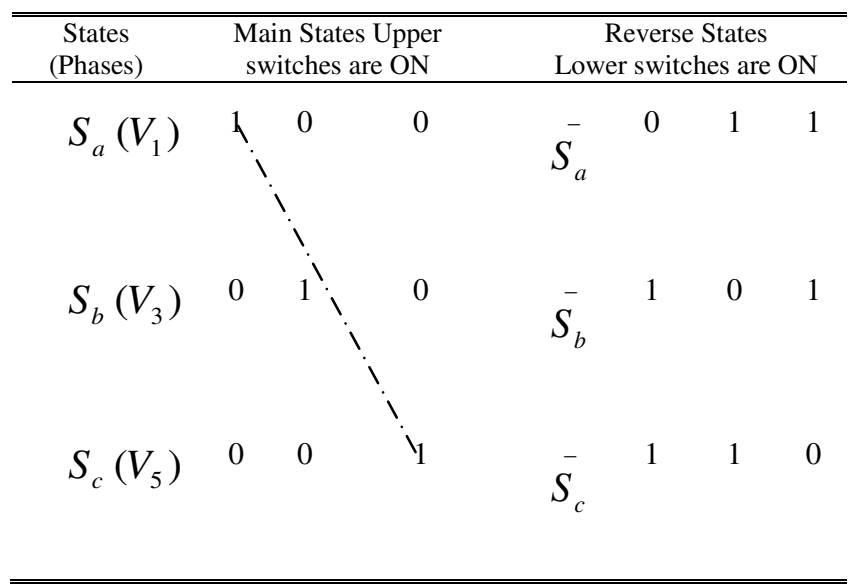

Journal of Engineering Sciences, Assiut University, Faculty of Engineering, Vol. 41, No. 3, May, 2013,E-mail address: jes@aun.edu.eg 
1126

M. A. Noman, S. A. Al-Ghamdi, Current controlled vsc for reactance modulation and voltage drop compensation on power transmission lines, pp. 1110 - 1126

التحكم بتيار مصدر الجها لتعديل مقاومة خط النقل ولتعويض الهبوط في الجها

(الملخص:

ـ تعديل مقاومـة خطوط نقل الطاقة الكهربائيـة لها تأثبر كبير على الجهود الكهربائية على الأحمـال أو في مر اكز

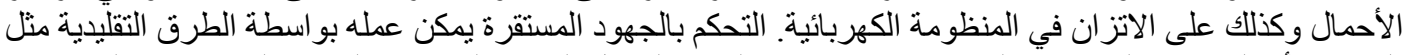

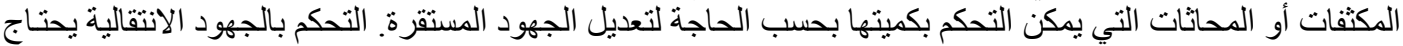

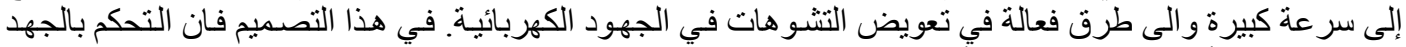

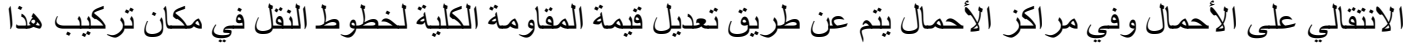

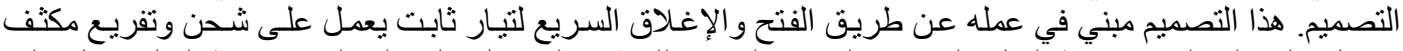

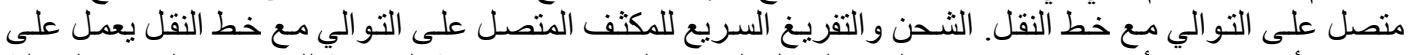

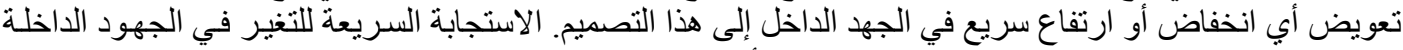

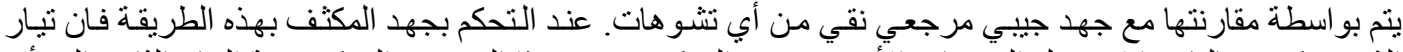

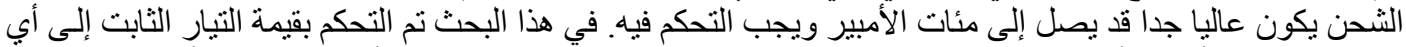
قيمة نرغب فيها أو إلي أي قيمة مطلوبة تضمن جودة التحكم بالجهد في نهاية خط النقل أو في مر اكز الأحمال.

Journal of Engineering Sciences, Assiut University, Faculty of Engineering, Vol. 41, No. 3, May, 2013,E-mail address: jes@aun.edu.eg 